\title{
Innovation trends in Romanian logistics providers industry
}

\author{
Cristian NEGRUȚIU \\ Bucharest University of Economic Studies, Bucharest, Romania \\ cristian_negrutiu@yahoo.com \\ Alexandra ONEA \\ Bucharest University of Economic Studies, Bucharest, Romania \\ ioana_alexandra_o@yahoo.com \\ Ruxandra BĂDESCU \\ Bucharest University of Economic Studies, Bucharest, Romania \\ ruxbadescu@gmail.com
}

\begin{abstract}
The purpose of this paper is to provide an overview of the innovation efforts employed by Romanian logistics service providers. Innovation in the service sectors, namely in logistics and supply chain, has gained increased interest from scholars in the last years. The implications in the business environment are to be noticed, since logistics and supply chain are the backbone of any business in the world. In this sense, the performance of the supply chain can make the difference between failure or success for many companies. A tendency that has become prominent in the last years is the outsourcing of a part or the entire supply chain to professional logistics providers. Romania makes no exception to this trend, although is relatively new and has been consolidated in the last few years with the emergence of major international players. However, in order to be performant, the logistics providers need to be innovative on a constant and consistent basis. This characteristic is emphasized by the relevant literature as a prerequisite for delivering a superior service to the customers. The aim of this paper is to complement the current research on this matter and determine the relationship between innovative efforts of the global/regional logistics services providers present on the Romanian market.

In order to understand this preoccupation, there have been reviewed the innovation and/or sustainability reports of 12 logistics services providers. The results identified common trends on innovation, but also few major differences. The present study is a first step in a larger research on innovation in Romania and it will be continued through several sectorial reviews.
\end{abstract}

Keywords: innovation, logistics providers, trends, customer service, supply chain.

\section{Introduction}

Logistics play a major role in the strategy of many businesses nowadays. Its crucial importance relies on the connection between profits maximization and overall customer service. The concept of logistics has gained new meanings over time and logistics management approaches business functions that comprise the overall "product transportation and information assessment", as highlighted by Oliva de Farias \& Akabane (2011). In addition, the authors identify three main segments of logistics, namely resources, logistics response and information technology. The latter has become increasingly important due to the revolutionary ways of business improvement and innovation nowadays. Innovation in logistics has become a reality that due to the constant need of customer relationship improvement.

Due to globalization and increased competition in the business environment, innovation applied in logistics can make the difference through value creation and competitive advantage. Knowledge sharing, knowledge dynamics (Bratianu \& Bejinaru, 2019, 2020), and the newness of products are a first step towards an innovative approach, but through logistics, this approach can 
become a palpable reality. As pointed out by Oliva de Farias \& Akabane (2011), a holistic approach in supply chain management is a prerequisite for creating customer satisfaction and developing firm performance. To this contributes the increased acceptance of outsourcing as a workable solution for overall improvement of service provided (Rodriguez et al., 2018). For the Romanian market, outsourcing is a reality that contributes to the significant growth of Romanian logistics industry. Third party logistics service providers are known for contributing to the overall efficiency of an organization by cost reduction, overall service improvement, and applied innovation in the focus on core activities. The increased use of information technology in developing shipping solutions, which translates through better coordination of activities among multiple supply chain parties, is a change that creates value and meets "customer service requirements" when compared with the traditional ways of transport and warehousing services (Rodriguez et al., 2018). Furthermore, Wang et al. (2016) point out the simplicity and lack of value of the traditional ways undertaken by old school logistics operators.

In the context of innovation and business reality, the accent falls more on collaboration and the "mediating role" that logistics service providers play nowadays. Besides operational efficiency mentioned previously, the pillars that characterize the logistics service providers are integration of customer operations and vertical and horizontal network development. Collaboration among different sectors is the primary feature that raises the interest of how network development and applied technologies work together in create innovation in logistics (Wang et al., 2016). Also, the ways in which these technologies are applied represent an additional concern. Rodriguez et al. (2018) describe many Enterprise Resource Planning (ERP) systems employed in order to deliver operational performance. Among these, warehouse management systems and other technological innovations such as bar code and radio frequency are mentioned as applicable solutions (Kontic \& Vidicki, 2018).

Therefore, the main research question of this paper is the existence or absence of a clear and constant focus on innovation in the LSP industry. Other research objectives refer to different types of innovation and their subsequent differences.

To our best knowledge, such a research is a first attempt for Romania. Even at global level, these studies are rare and provide only some insights, by following few patterns on innovation. We believe that a complete snapshot of innovation in LSP industry will benefit both academia and practitioners.

\section{Literature review}

\section{Innovation in business context}

Innovation is considered one of the main attributes for long-term business success and a significant source of competitive advantage for companies nowadays. Considering the multiple challenges faced by organizations in today's market, the adoption of an innovative approach may result in multiple benefits. In this sense, scholars have studied innovation management in order to provide real solutions to the business environment. While there is a clear separation between technological and non-technological innovation, innovation management itself falls under the second category. It is considered to be a complex part of the overall achievement of competitive advantage and closely connected to the innovation alignment, an important part of service innovation. (Khosravi et al., 2019; Wallenburg et al., 2019).

The literature presents several concepts when addressing the issue of organizational innovation with the purpose of creating a theoretical framework. In this regard, organizational innovation represents from a managerial point of view, a set of rules and beliefs that describe the functioning of knowledge management, while also providing the necessary tools for directing the 
strategy of the organization towards new endeavors. Furthermore, the organizational innovation is closely linked with the product innovation, since it manages to provide competitive value and prompt reactions to the external environment. (Wang \& Chen, 2020). In addition, product innovation is one of the most notorious types of innovations, since it represents the basis of both new, emergent businesses as well as established ones. The later adopt product innovation in order to increase their economic and social value by developing processes that strengthen the $R \& D$ efforts. (Edwards-Schachter, 2018). R\&D is considered an integral part of innovation efforts employed by companies while also being closely connected with public policy intentions. In this sense, patents represent the main focus of innovative approaches. Europe 2020 strategy promotes the introduction of innovative ideas on the market, thus opening the gate of cooperation and collaboration between industry and policy makers. (Pegkas et al., 2019). A key part of product innovation is defined by patens and consequently, new product development, thus establishing an interdependent relationship with organizational innovation, as mentioned by Wang and Chen (2020).

A long-term challenge, patenting, resulting from complex innovation provides a series of benefits and subsequent drawbacks (Pegkas et al., 2019; Kumaar \& Singh, 2019). In terms of benefits, complex innovations resulting in patents, provide a clear direction for future knowledge and development in specific areas, while also contributing to the society in terms of economic advantages, such as job creation, reform implementation, productivity growth (Pegkas et al., 2019). In terms of drawbacks, patent creation results in difficulties for small and medium firms, which lack the necessary means (both financial and knowledge wise) to provide arduous innovations (Kumaar \& Singh, 2019).

In order to enhance performance as a whole, Brown et al. (2019) propose a new way of incorporating innovation. In this sense, system innovations combine several business areas such as technological, organizational, research and development that result in the creation of a new business model. The adoption of such business models implies the collaboration between various players in the business environment, the "innovation intermediaries", which occupy several roles within the organization. These can lead to the creation of business model innovation, a concept that represents a source of innovation in itself. Apart from traditional business models, the business model innovation comprises several directions, such as technological, sustainable innovation and development of the corporate sector in emerging economies. (Edwards-Schachter, 2018). In accordance with today's references to innovation, the business model innovation connects the agile and resourceful business environment with a completely new system that aims to redesign the business model into an innovative framework. Its complexity addresses different business models and transforms business ecosystems in value creation networks. (To et al., 2019). The adoption of such business models is associated with new technologies and disruptive innovation. However, these notions are viable only in an economic environment. Therefore, the interdependence of all the systems involved in the process is of the utmost importance. Disruptive innovation is related with the "newness" of the products and processes introduced, but it should be closely linked with market value. This connection makes the difference between failure and success, as described by Zach et al. (2020). Apart from market value, when adopting a disruptive innovative approach, companies should take into consideration all the aspects involved in the process. In this sense, organizations should evaluate their internal processes, capabilities and the feasibility of their innovative activities. In addition, strategy, collaboration and company's culture have a major role in the overall success of the adopted innovation approach. (Radnejad \& Vredenburg, 2019). 
As described by Vega and Chiasson (2019), strategy is a key component when defining the direction towards which companies should head. However, the literature lacks in illustrating the exact mechanism through which companies can apply a strategic approach and achieve a disruptive newness in their products. Therefore, an incremental dimension is suggested to be more effective by Zach et al. (2020). The incremental innovation refers to small changes that create business results in terms of market value. In addition, Vega and Chiasson (2019) propose a system of innovation, namely a general framework that comprises all the active parts involved in the innovation process. This leads to the concept of open innovation, which benefits from increased interest both from academia as well as the business environment. As highlighted by Mei et al. (2019), open innovation applies better to large corporations and implies the whole "ecosystem" that operates in order to create market value through products or services. An important focus is placed on the knowledge sharing with external entities that results both in financial and strategic outcomes (Masucci et al., 2020). Due to the complexity of the innovation process and the risks associated with it however, the outbound innovation process has its drawbacks, since too much openness can lead to exposure to competitors. In this sense, Frishammar et al. (2019) introduce a structure that aligns resources and capabilities of the organizations with the concept of collaboration. The authors propose digitalization as a beneficial way to engage with stakeholders and customers as well.

\section{Innovation in logistics and supply chain}

With a focus on applied business sectors, digitalization in logistics is enclosed in the overall process of value creation. Considering that logistics are closely embedded in the service innovation category, the relationships formed between buyer and supplier are crucial (Wallenburg et al., 2019). Service innovation differs from other types of innovation, since it comprises a sum of activities that are more prone to incremental changes rather than radical ones. Combining people, processes and different skills and materials, service innovation can be considered an intermediary between customer needs and company's strategy (EdwardsSchachter, 2018). Bringing the focus on the concept of innovation alignment, namely the collaboration between buyers and suppliers, Wallenburg et al. (2019) highlight the benefits of a "joint understanding" between the parties involved in the process. This alignment can be noticed in the agile process as well, where managers communicate directions and coordinate the process through daily meetings.

Skippari et al. (2017) further develop the concept of innovation in supply chains, by highlighting its presence mostly at buyer-seller level. The authors highlight the idea according to which the collaboration is based on forming relationships, which has as basis a cognitive process and framework. In addition, each supply chain member should act accordingly to the innovation orientation adopted at managerial level and the consequent organization's ability to innovate. Furthermore, the focus on agile methods of innovation suggests increased impact of the subsequent adopted methods. It is a process closely related to digitalization, which targets flexibility as main feature. The complexity of establishing all the steps when creating a project plan is now more approachable, since agile methods emphasize compliance and customer orientation (Niewohner et al., 2019). In supply chains, innovative approaches should embrace the assimilation of three main directions: internal, customers and supplier. In an environment characterized by rapid changes, companies should focus more on innovation. When highlighting the importance of creating internal value and producing competitive advantage, the integration of suppliers is considered to have a positive impact on the overall business outcome (Lii \& Kuo, 2016).

DOI: 10.2478/picbe-2020-0077, pp. 807-818, ISSN 2558-9652| Proceedings of the $14^{\text {th }}$ International Conference on Business Excellence 2020 
Digitalization is at the center of any innovation endeavor. Key terms such as "Internet of Things", "Smart Services", "Cloud Working" are constituents of the overall framework of machine and environment interaction (Niewohner et al., 2019). With the introduction of Industry 4.0, that comprises the combination of products, services and processes, Logistics 4.0 is a concept that can easily be deducted from the new needs that regard logistics. It is a system that still needs further development from academia and business environment as well. It is believed that this system will provide a better connection with customers and will revolutionize the way in which logistics was perceived. In addition, besides the intelligent systems employed in order to create customer satisfaction, sustainability is also a key term that plays an important role in the nowadays business environment (Torbacki \& Kijewska, 2019).

\section{Innovation in logistics services providers}

Following the idea of customer-oriented service, innovation in logistics service providers could have positive effects on the overall logistics service performance. The implementation of such innovation however, is not yet a reality in most companies due to the lack of involvement in innovation management. Also, the barriers in innovation management that many logistics service providers face are to be taken into account. These barriers refer to the lack of clear guidelines of innovation adoption, the inefficiency of knowledge transfer and the difficulty of testing innovative concepts (Wagner \& Sutter, 2012).

In order to address this issue, Neutzling et al. (2018) propose an incremental approach that focuses on the "organizational transformation" in the sense of integrating sustainable innovation in the company's culture and thus, generating value. This approach can influence the relationship with suppliers and create competitive advantage. However, further research is needed in order to determine the exact manner in which innovation in logistics service providers can be implemented. In this sense, besides the correlation between product and service innovation, the focus on organizational issues, integrating collaboration and sustainability as objectives and detailing the operational process are factors that still need in depth analysis (Wagner \& Sutter, 2012; Neutzling et al., 2018).

\section{Methodology}

In order to achieve the objectives of this study, there has been performed a desk research of the official reports made publicly available by the largest LSP's that are present in Romania. It should be noted that innovation is present in various reports, ranging from dedicated sections to corporate social responsibility (CSR) reports. This reflects how the LSP approach innovation either as a standalone preoccupation, that gives focus or as part of the CSR theme, which directs more towards responsible and sustainable innovation.

The LSPs have been selected based on two cumulative criteria: global/regional presence and significant market share in Romania. Put in other way, global/regional players with no presence in Romania were excluded (ex. DHL); vice versa, strong providers with operations only in Romania were not took into account. Public charts provided by specialty media (ex. Cargo Magazin, Traffic Media) were used also in selection of the LSP's.

Based on the above considerations, the sample selected is representative for the Romanian logistics providers industry.

The selected companies are:

1. DSV Solutions

2. DB Schenker

3. Kuehne + Nagel

DOI: 10.2478/picbe-2020-0077, pp. 807-818, ISSN 2558-9652| Proceedings of the $14^{\text {th }}$ International Conference on Business Excellence 2020 
4. Gebruder Weiss

5. FM Logistic

6. Mainfreight

7. KLG

8. Quehenberger

9. H. Essers

10. Gefco

11. Geodis

12. XPO

PICBE $\mid 812$

\section{Results and discussions}

The research showed a different degree of preoccupation for innovation. Some companies present innovation in a separate report and clearly highlight specific directions for innovation. Others treated as a sub-chapter in the sustainability report and are more general as regard to directions. Therefore, where applicable, the results will be summarized in tables, otherwise just a discussion.

\section{DSV Solutions}

DSV is one the largest LSP's in the world. Through the recent acquisitions of UTI and Panalpina, the Group has reached a truly global presence. DSV is present in Romania since 1994, providing a full range of transport and logistics services.

Every year, DSV issues a report called "Forward Logistics" in which it presents the status of the major innovations happening in the industry. The report starts with a very clear headline - the logistics industry needs to innovate. The main directions for innovation are summarized in Table 1 .

Table 1. Directions for innovations in DSV

\begin{tabular}{|l|l|l|}
\hline No & Direction & Characteristics \\
\hline 1 & Tracking in real time & $\begin{array}{l}\text { Logistics providers are getting closer to solving the complexity } \\
\text { of tracking cargo shipments in real-time. This involves cutting- } \\
\text { edge tools like RFID and barcode systems integrated into cloud- } \\
\text { based systems. Communication and integration with customers' } \\
\text { systems is also essential and this is linked with next } \\
\text { characteristic }\end{array}$ \\
\hline 2 & Blockchain & $\begin{array}{l}\text { A blockchain can be thought of as a decentralized, } \\
\text { cryptographically secure, verified digital ledger where each } \\
\text { entry is permanent and viewable in real-time by every interested } \\
\text { party. In the increasingly complex world of logistics, blockchain } \\
\text { technology can provide real-time transparency and reduce } \\
\text { manual processes }\end{array}$ \\
\hline 3 & Electrification & $\begin{array}{l}\text { Battery-powered electric vehicles are expected to take a } \\
\text { growing share of the automotive market over the coming years, } \\
\text { but uncertainties in the market make their future hard to predict. }\end{array}$ \\
\hline 4 & Artificial intelligence & $\begin{array}{l}\text { AI is steadily making its way into many aspects of logistics: } \\
\text { vehicles, traffic, warehouses, customs, business processes, } \\
\text { predictive reporting }\end{array}$ \\
\hline 5 & $\begin{array}{l}\text { Big andictive analytics } \\
\text { predata }\end{array}$ & $\begin{array}{l}\text { The ability to understand the huge amount of data of a supply } \\
\text { chain is proving invaluable as pressure from customers to get } \\
\text { things right is escalating. A good reporting system is vital, as } \\
\text { the ability to keep things simple, when they are in fact complex, }\end{array}$ \\
\hline
\end{tabular}

DOI: 10.2478/picbe-2020-0077, pp. 807-818, ISSN 2558-9652| Proceedings of the $14^{\text {th }}$ International Conference on Business Excellence 2020 


\begin{tabular}{|c|c|c|}
\hline & & is critical to logistics reporting. \\
\hline 6 & 3D printing & $\begin{array}{l}\text { 3D printing technology has developed incredibly swiftly over } \\
\text { the past decade. The raw materials used in 3D printers are now } \\
\text { so refined they are accelerating the advancement of 3D printing } \\
\text { technology. }\end{array}$ \\
\hline 7 & E-fulfilment & $\begin{array}{l}\text { E-commerce sales are expected to continue skyrocketing over } \\
\text { the next few years, with a recent projection suggesting they will } \\
\text { reach up to } \$ 4.9 \text { trillion worldwide in } 2021 \text { from a projected } \\
\$ 3.5 \text { trillion in } 2019 \text {. }\end{array}$ \\
\hline 8 & $\begin{array}{l}\text { Digital freight } \\
\text { brokerage platforms }\end{array}$ & $\begin{array}{l}\text { In recent years, a growing number of start-ups have eyed-up the } \\
\text { road freight brokerage process aiming to simplify what is a } \\
\text { rather complex system through digital interfaces. Examples of } \\
\text { such tools are: freight exchanges, tool providers and digital } \\
\text { resellers }\end{array}$ \\
\hline 9 & Sustainability & $\begin{array}{l}\text { With transport being one of the most carbon-intensive activities, } \\
\text { individuals and businesses are increasingly seeking more and } \\
\text { faster change. Speeding up the sector's transition towards } \\
\text { greener alternatives is a shared responsibility that needs to } \\
\text { include political steps. }\end{array}$ \\
\hline 10 & Robotics & $\begin{array}{l}\text { Automation and robotics have become an integral part of } \\
\text { operations in several warehouses. Traditional activities like } \\
\text { picking, scanning, sorting, packing etc are now performed by } \\
\text { machines integrated into warehouse management software }\end{array}$ \\
\hline 11 & $\begin{array}{l}\text { Fourth party logistics } \\
\text { (4PL) }\end{array}$ & $\begin{array}{l}\text { A 4PL is a non-asset based, neutral supply chain orchestrator } \\
\text { who assembles resources, capabilities, and technology to } \\
\text { design, build and operate more intelligent supply chains. }\end{array}$ \\
\hline 12 & Cybersecurity & $\begin{array}{l}\text { In today connected world, security of data is more important } \\
\text { than ever }\end{array}$ \\
\hline
\end{tabular}

PICBE | 813

Source: Authors' own research, adapted after DSV Forward Logistics Report 2019

2. DB Schenker is the world's leading global logistics provider. Through the acquisition of Romtrans, it secured a top position also in Romania.

DB Schenker has a dedicated innovation tab, with clear focus on start-ups. They don't issue an innovation report per se, but instead points to some future trends. These are presented in Table 2:

Table 2. Directions for innovations in DB Schenker

\begin{tabular}{|l|l|l|}
\hline No & Direction & Characteristics \\
\hline 1 & Autonomous driving \& platooning & $\begin{array}{l}\text { Autonomous trucks will become a reality of the } \\
\text { future }\end{array}$ \\
\hline 2 & 3D-Printing & DB Schenker has a network of 3D partners \\
\hline 3 & Virtual Supply Chain Management & $\begin{array}{l}\text { The use of intelligent algorithms and big data } \\
\text { processing can optimize the supply chains of the } \\
\text { customers }\end{array}$ \\
\hline 4 & Predictive Analytics & $\begin{array}{l}\text { Recognizing patterns in large data sets does not only } \\
\text { help to improve the operations but also predict } \\
\text { supply chain dynamics of the customers. }\end{array}$ \\
\hline
\end{tabular}

Source: Authors' own research, adapted after DB Schenker innovation webpage

DOI: 10.2478/picbe-2020-0077, pp. 807-818, ISSN 2558-9652| Proceedings of the $14^{\text {th }}$ International Conference on Business Excellence 2020 


\section{Kuehne + Nagel}

Kuehne + Nagel has grown into one of the world's leading logistics providers, ranking in top 5 for all major services. In Romania, the Group is present more in seafreight and airfreight services. Kuehne + Nagel has established its own venture capital fund, in association with a partner. The Fund seeks to actively support early or growth stage businesses seeking to transform the supply chain and logistics industry utilizing cutting-edge technology. More specifically, the Fund seeks potentially disruptive and transformative technologies and business models in areas like AI/Predictive Analytics, IoT, Shared Economy models, Computer Vision/Analytics, Robotics. The Fund has created also other initiatives to support innovation and new technologies, like The Centre of Gravity for Global Emerging Supply Chain Technology (GESCT).

\section{Gebruder Weiss}

Gebruder Weiss is a family-run company, with strong presence in Eastern Europe. Although they don't have a dedicated innovation page, GW values are based on sustainability on three pillars: economic, environmental and social

\section{FM Logistic}

FM Logistic is a French company that gain an important market share in Romania. Their sustainable development strategy is based on 4 pillars, with a highlight on innovation.

Table 3. Sustainable development strategy in FM Logistic

\begin{tabular}{|l|l|l|}
\hline No & Pillar & Actions \\
\hline 1 & $\begin{array}{l}\text { Economic Pillar - Imagining } \\
\text { tomorrow's logistics chain }\end{array}$ & $\begin{array}{l}\text { Innovation in logistics chain practices } \\
\text { Sponsoring skills acquisition in the logistics } \\
\text { trade } \\
\text { Contributing to job creation and the local } \\
\text { economy in each country }\end{array}$ \\
\hline 2 & $\begin{array}{l}\text { Environmental pillar - Giving pride } \\
\text { of place to environmental } \\
\text { performance }\end{array}$ & $\begin{array}{l}\text { Reducing the carbon footprint of the business } \\
\text { Decreasing energy consumption } \\
\text { Developing green services for the customers }\end{array}$ \\
\hline 3 & $\begin{array}{l}\text { Societal Pillar - Contributing to the } \\
\text { development of the local economy }\end{array}$ & $\begin{array}{l}\text { Developing partnerships to support local causes } \\
\text { Developing projects that contribute to society } \\
\text { Promoting professional integration for the } \\
\text { underprivileged }\end{array}$ \\
\hline 4 & $\begin{array}{l}\text { Social Pillar - Preparing the staff to } \\
\text { become the foundation of FM } \\
\text { commitment }\end{array}$ & $\begin{array}{l}\text { Developing the professional skills of the people } \\
\text { Ensuring safety at work for the staff } \\
\text { Giving all the personnel access to the health } \\
\text { system }\end{array}$ \\
\hline
\end{tabular}

Source: Authors' own research, adapted after FM corporate webpage

\section{Mainfreight}

Mainfreight is a global logistics provider, with origin in New Zeeland. In Romania, they entered through the acquisition of Wim Bosman. The innovation is part of the CSR report, but very limited. 


\section{7. $K L G$}

KLG is a Dutch logistics provider with significant presence in Romania. The innovation part is very limited and is contain in the CSR report.

\section{Quehenberger}

Quehenberger is an Austrian logistics provider that increased its market in Romania in the last PICBE | 815 years, especially in the fashion industry. They have a dedicated tab on innovation and quality, separated from the CSR. However, the directions mentioned are quite general, referring to digitalization and software solutions, smart logistics and few examples on some specific tools.

\section{H. Essers}

H. Essers is a family-run Belgian company and one the first logistics providers in Romania. They are focused mainly on transport, with some operations in logistics. The CSR report is quite comprehensive, but only mentions innovation briefly and without many details.

\section{Gefco}

GEFCO Group is today the $\mathrm{N}^{\circ} 1$ European leader in finished vehicle logistics, and a top 10 global partner in multimodal supply chain solutions. Innovations is treated separately versus CSR, but under the umbrella of what Gefco calls "engineering performance". The main points mentioned here are flow optimization, 4PL solutions, traceability and intelligence tools.

\section{Geodis}

Geodis is one world leading logistics provider, with a strong presence in Romania, especially in the retail industry. Their strategy is driven by business excellence and is inspired by the model recommended by the European Foundation for Quality Management (EFQM). Although directions for innovations are not explicitly mentioned, Geodis presents several case studies of advanced practices, such as use of robots and drones in the warehouses.

\section{2. $X P O$}

XPO is a top ten global provider of transportation and logistics services, with a highly integrated network of people, technology and physical assets. Innovation plays a very important role in XPO operations and is focused on four areas: automation and intelligent machines, visibility and customer service, the digital freight marketplace and dynamic data science.

The desk research on innovation of logistics provider have provided significant insights into this matter. The main findings common to all companies analyzed are:

1. There is a high interest and motivation to advance innovation

2. Innovation as key ingredient for success and customer satisfaction

However, there are some findings that differentiate the high performers versus the low performers:

1. Only 7 out of 12 companies present innovation separated versus the more general topic of sustainability. Therefore, they differentiate between practices that really fosters new way of doing things instead of just complying to (for ex.) environmental factors.

2. Only 4 out of 12 companies present concrete directions for innovation, and not just general matters. It is not by coincidence that this are the largest providers in the world 
(present also in Romania), therefore we can say that there is a direct connection between success and innovation.

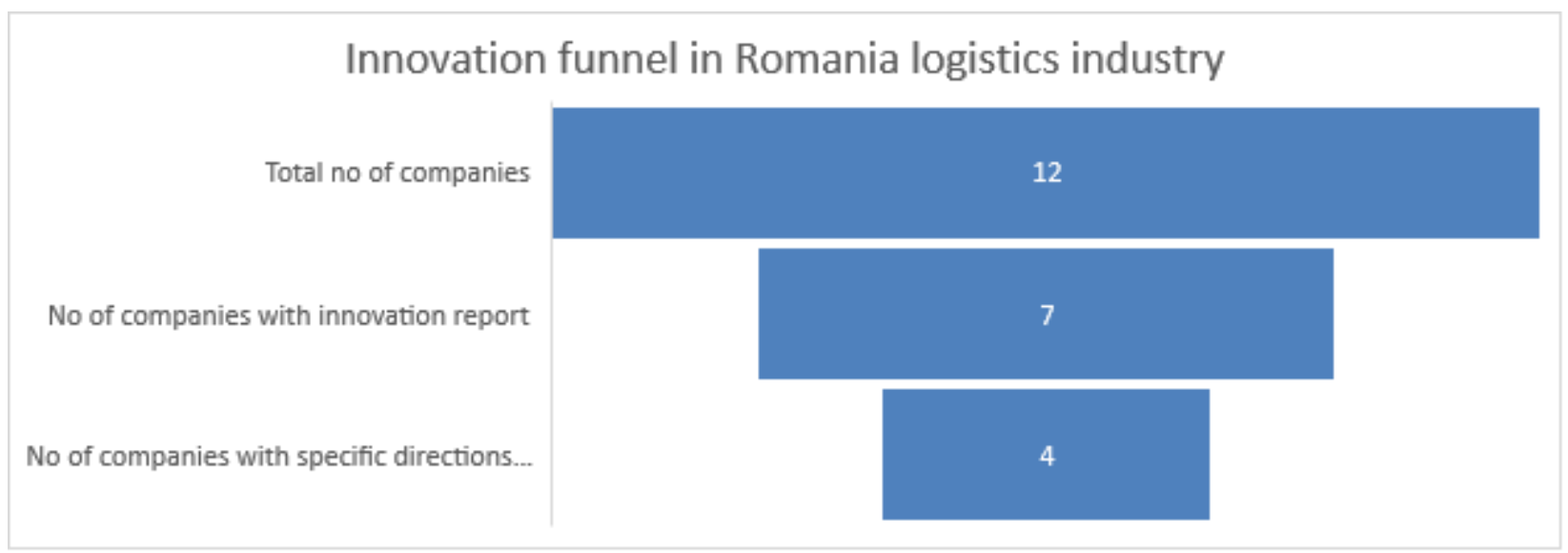

Figure 1. Innovation funnel in Romania logistics industry

Source: Authors' own research

In terms of concrete directions for innovation, there are few of them that are mentioned and common to all the 4 companies. These are: traceability or tracking in real time, autonomous and electric vehicles, predictive analytics and big data, 3D printing and digital freight platforms.

\section{Conclusion}

The study is important for both academia and practitioners because it reveals the main directions for innovation in logistics industry. For each direction there is a possibility for a more in-depth research. Practitioners have a complete snapshot of innovation trends and now they can measure their gap in comparison with best in class.

The main limitation of the research is the due to the fact that we performed only a desk research. In other words, we find out what the LSP's say about the innovation and not what they are really doing in practice. Also, real applicability of the concepts in Romania was not analysed, as the authors researched only corporate reports. The limitation will be addressed in a future study, where the authors will deploy a questionnaire to the LSP's selected in the current research.

\section{References}

Bratianu, C., \& Bejinaru, R. (2019). The theory of knowledge fields: A thermodynamics approach. Systems, 7(2), 20, 1-12.

Bratianu, C. \& Bejinaru, R. (2020). Knowledge dynamics: A thermodynamics approach. Kybernetes, 49(1), 6-21.

Brown, D., Kivimaa, P. \& Sorrell, S. (2019). An energy leap? Business model innovation and intermediation in the 'Energiesprong' retrofit initiative. Energy Research \& Social Science, 58, 101253.

DB Schenker Innovation \& Digitalization Insights, https://www.dbschenker.com/global/about/innovation-digitalization/innovationdigitalization-insights, accessed on 15 December 2019.

DSV Forward Logistics Report 2019, https:/www.dsv.com/downloads-and-services/forwardlogistics-report, accessed on 17 December 2019. 
Edwards-Schachter, M. (2018). The nature and variety of innovation. International Journal of Innovation Studies, 2, 65-79.

FM Logistic web page, http://sustainable-development.fmlogistic.com/en/index.html, accessed on 19 December 2019

Frishammar, J., Richtner, A., Brattstrom, A., Magnusson, M. \& Bjork, J. (2019). Opportunities and challenges in the new innovation landscape: Implications for innovation auditing and innovation management. European Management Journal, 37, 151-164.

Khosravi, P., Newton, C. \& Rezvani, A. (2019). Management innovation: A systematic review and meta-analysis of past decades of research. European Management Journal, 37, 694707.

Kontic, L. \& Vidicki, D. (2018). Strategy for digital organization: Testing a measurement tool for digital transformation. Strategic Management, 23(2), 29-35.

Kumaar, S. \& Singh, B. (2019). Barriers to the international diffusion of technological innovations. Economic Modelling, 82, 74-86.

Lii, P. \& Kuo, F. (2016). Innovation-oriented supply chain integration for combined competitiveness and firm performance. International Journal of Production Economics, $174,142-155$.

Masucci, M., Brusoni, S. \& Cennamo, C. (2020). Removing bottlenecks in business ecosystems: The strategic role of outbound open innovation. Research Policy, 49, 103823.

Mei, L., Zhang, T. \& Chen, J. (2019). Exploring the effects of inter-firm linkages on SMEs' open innovation from an ecosystem perspective: An empirical study of Chinese manufacturing SMEs. Technological Forecasting \& Social Change, 114, 118-128.

Neutzling, D. M., Land, A., Seuring, S. \& Machado do Nascimento, L. F. (2018). Linking sustainability-oriented innovation to supply chain relationship integration. Journal of Cleaner Production, 172, 3448-3458.

Niewohner, N., Asmar, L., Wortmann, F., Roltgen, D., Kuhn, A. \& Dumitrescu, R. (2019). Design fields of agile innovation management in small and medium sized enterprises. Procedia CIRP, 84, 826-831.

Oliva de Farias, O. \& Akabane, G. K. (2011). Innovation and creativity on logistics besides TRIZ methodology. Procedia Engineering, 9, 724-729.

Pegkas, P., Staikouras, C. \& Tsamadias, C. (2019). Does research and development expenditure impact innovation? Evidence from the European Union countries. Journal of Policy Modeling, 41, 1005-1025.

Radnejad, A. M. \& Vredenburg, H. (2019). Disruptive technological process innovation in a process-oriented industry: A case study. Journal of Engineering and Technology Management, 53, 63-79.

Rodriguez, A. C., Martins, R. S., Wanke, P. F. \& Siegler, J. (2018). Efficiency of specialized 3PL providers in an emerging economy. International Journal of Production Economics, 205, 163-178.

Skippari, M., Laukkanen, M. \& Salo, J. (2017). Cognitive barriers to collaborative innovation generation in supply chain relationships. Industrial Marketing Management, 62, 108-117.

To, C. K. M., Au, J. S. C. \& Kan, C. W. (2019). Uncovering business model innovation contexts: A comparative analysis by fsQCA methods. Journal of Business Research, 101, 783-796.

Torbacki, V \& Kijewska, K. (2019). Identifying key performance indicators to be used in Logistics 4.0 and Industry 4.0 for the needs of sustainable municipal logistics by means of the DEMATEL method. Transportation Research Procedia, 39, 534-543. 
Vega, A. \& Chiasson, M. (2019). A comprehensive framework to research digital innovation: The joint use of the systems of innovation and critical realism. Journal of Strategic Information Systems, 28, 242-256.

Wagner, S. M. \& Sutter, R. (2012). A qualitative investigation of innovation between third-party logistics providers and customers. International Journal of Production Economics, 140, 944-958.

Wallenburg, C. M., Johne, D., Cichosz, M., Goldsby, T. J. \& Knemeyer, A. M. (2019).

Alignment mechanisms for supplier-initiated innovation: Results from the logistics service industry. Journal of Purchasing and Supply Management, 25, 100-575.

Wang, F. \& Chen, K. (2020). Do product imitation and innovation require different patterns of organizational innovation? Evidence from Chinese firms. Journal of Business Research, 106, 60-74.

Wang, X., Persson, G. \& Huemer, L. (2016). Logistics Service Providers and Value Creation Through Collaboration: A Case Study. Long Range Planning, 49, 117-128.

Zach, F. J., Nicolau, J. L. \& Sharma, A. (2020). Disruptive innovation, innovation adoption and incumbent market value: The case of Airbnb. Annals of Tourism Research, 80, 102818. 